保健物理, 10, 211 214（1975）

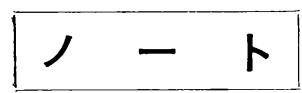

$\mathrm{Ge}(\mathrm{Li})$ 半導体検出器の測定効率

本郷昭三*1, 野田 豊*1, 横田繁明*2

(1975 年 8 月 18 日受理)

Efficiency of $\mathrm{Ge}(\mathrm{Li})$ Detector

Syozo Hongo, ${ }^{* 1}$ Yutaka NodA, ${ }^{* 1}$ Shigeaki YoKota ${ }^{* 2}$

I 序

優れた $\gamma$ 線エネルギー分解能をもつ $\mathrm{Ge}(\mathrm{Li})$ 半導体検 出器は, 化学処理を必要とせず, 多核種を分離定量で き, 安全管理等保健物理的な面から, あるいは一般研究 に新いても, 利用性は大きい。上記の長所を生かして, 種々の核種を含む, 種々の形状の試料が半導体検出器を 用いて定量され, 種々の条件下で測定効率を求めておく ことが必要となっている。測定効率を実験的に求める場 合, あらかじめ, その值が推定できれば, 測定条件 $(r$ 線エネルギーや検出器と試料の相対位置等) を必要最小 限にすることによって，多くの手数を減ずることができ る。また，効率が求められていない条件下で定量する必 要が生じた場合，すなわち緊急時や相対的な值が主たる 問題の場合, 測定効率を推定することによって,オーダ をつかむことが可能となる。筆者らは $28.3 \mathrm{cc}$ の同軸型 $\mathrm{Ge}(\mathrm{Li})$ 半導体検出器 (Fig. 1) の全エネルギーピーク効 率を，市販の標準線源*3を用いて実験的に求めた。これ らの結果から，効率較正の行われていない条件に対する 全エネルギーピーク効率の推定や, 他の検出器に対する 全ェネルギーピーク効率（以下効率と記す）の推定に資 すべく検討を行った。

*1 放射線医学総合研究所; 千葉市穴川 4-9-1 ( National Institute of Radiological Sciences; 9-1, Anagawa 4-chome, Chiba-shi, Chiba-ken.

*2 東海大学医学部; 神奈川県伊势原市望星台 (T259-11) Tokai University School of Medicin, Boseidai, Isehara-shi, Kanagawa-ken.

*3 The Radio Chemical Center 製, 各々の線源の精度 $2 \%$ 以内。

*4後述 ( 2 ) 式参照, 本検出器の場合, $\Delta X=2 \mathrm{~cm}$ となり, $R$ はほ核検出器中心からの距離とみなすことができた。

\section{II 測定および結果}

\section{1. 検出器-線源の相対位置に対する効率の変化}

${ }^{54} \mathrm{Mn}(r: 835.3 \mathrm{keV})$ を用いて, 検出器-線源の相対位 置に対する効率を調べた。その結果を Fig. 2 亿示す。 同図で $X$ 軸は検出器中心軸から, $Y$ 軸は検出器キャッ プから, 線源までの距離を表わし， $Z$ 軸は中心軸上 5 $\mathrm{cm}$ のところを 1.0 とした相対効率を表わしている。各 測定点の相対効率の值に, 検出器の実行中心からの距離 の 2 乗 $\left(R^{2}=\left\{(X+\Delta X)^{2}+Y^{2}\right\}\right)^{* 4}$ を乗ずるとほぼ一定 值となり, Fig. 2 の薄墨の部分に拈いては, すべての 值は平均值に対して $\pm 4 \%$ 以内にある。同样に ${ }^{137} \mathrm{Cs}(\gamma$ : $661.6 \mathrm{keV})$ 抢よび ${ }^{60} \mathrm{Co}(\gamma: 1,332 \mathrm{keV})$ について子実 験を実施したが，測定值に $R^{2}$ を乗ずると，それぞれの 值は平均值の $\pm 3 \%$ 打よび $\pm 4 \%$ 以内となった。

しかし ${ }^{241} \mathrm{Am}(\gamma: 59.5 \mathrm{keV})$ の場合には, 21 点の測 定に対して平均值の $\pm 4 \%$ に入る点は全体の $1 / 3$ 以下 で, 平值均に対して最大の誤差は $25 \%$ にも達し, 前述 の比較的高いエネルギーの $\gamma$ 線に対する効率変化とはか なり異なっている。特に顕著な差は, 中心軸上から離れ た点 $(X=3,4,5)$ にみられる (Fig. 3 参照)。この主た る原因は $\gamma$ 線のエネルギーが低いため, 線源から放出さ

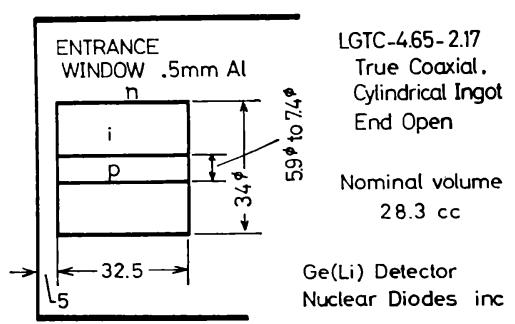

Fig. 1 Schematic diagram of the $28 \mathrm{cc} \mathrm{Ge}(\mathrm{Li})$ detector. unit : $\mathrm{mm}$. 


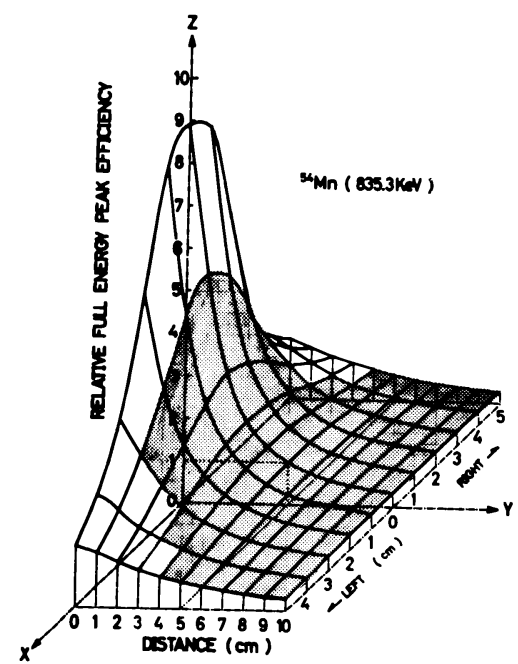

Fig. 2 Relative full energy peak efficiency of the $28 \mathrm{cc} \mathrm{Ge}(\mathrm{Li})$ detector for $\mathrm{Mn}-54$ (835.3 $\mathrm{keV}$ ) gamma-ray.

$\mathrm{X}$-axis : radial distance from source to the detector axis, Y-axis : vertical distance from source to the detector end cap.

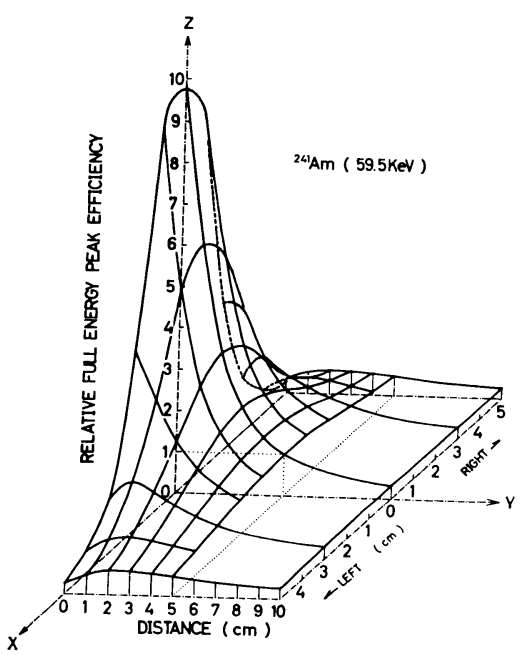

Fig. 3 Relative full energy peak efficiency of the $28 \mathrm{cc} \mathrm{Ge}(\mathrm{Li})$ detector for Am-241 (59.5 $\mathrm{keV}$ ) gamma-ray.

れた $\gamma$ 線が検出器の有効部分に達する間に比較的大きい 吸収（キャップ部アルミ等）が起り，その割合が線源の 位置によって異なることと，実行中心が比較的高いエネ ルギーをもつ $\gamma$ 線の場合と異なることによるものと考党 られる。

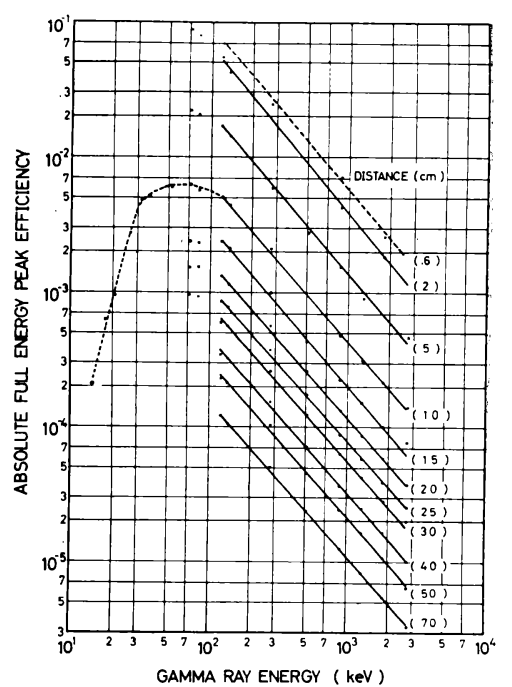

Fig. 4 Absolute full energy peak efficiency of the $28 \mathrm{cc} \mathrm{Ge}(\mathrm{Li})$ detector.

Parameter: distance from source to the $\mathrm{Ge}$ (Li) detector surface.

Table 1 Estimated value of $K, B$ and coefficient of correlation.

\begin{tabular}{lccc}
\hline $\begin{array}{c}\text { Distance } \\
(\mathrm{cm})\end{array}$ & $K$ & $B$ & $\begin{array}{c}\text { Coefficient } \\
\text { of correlation }\end{array}$ \\
\hline 0.6 & 1.19 & 22.6 & 0.9988 \\
2 & 1.23 & 18.8 & 0.9999 \\
5 & 1.19 & 5.09 & $\prime \prime$ \\
10 & 1.17 & 1.42 & $\prime \prime$ \\
15 & 1.18 & 0.702 & $\prime \prime$ \\
20 & 1.15 & 0.335 & $\prime \prime$ \\
25 & 1.15 & 0.214 & $\prime \prime$ \\
30 & 1.16 & 0.165 & $\prime \prime$ \\
40 & 1.15 & 0.0952 & $\prime \prime$ \\
50 & 1.15 & 0.0624 & $\prime \prime$ \\
70 & 1.15 & 0.0300 & \\
\hline
\end{tabular}

\section{2. $\boldsymbol{\gamma}$ 線エネルギー $(\boldsymbol{E})$ に対する効率の変化}

$2,734.4 \mathrm{keV}, 1,836.1 \mathrm{keV}, 1,274.5 \mathrm{keV}, 898.0 \mathrm{keV}$, $511 \mathrm{keV}, 279.2 \mathrm{keV}, 136.3 \mathrm{keV}$ および $121.9 \mathrm{keV},\left({ }^{88} \mathrm{Y}\right.$, ${ }^{22} \mathrm{Na},{ }^{203} \mathrm{Hg}$ 抢よび $\left.{ }^{57} \mathrm{Co}\right)$ の 線を用いて, エネルギー に対する効率の変化を調べた。その結果を Fig. 4 に示 す。 $121.9 \mathrm{keV}\left({ }^{57} \mathrm{Co}\right)$ から $2,734.4 \mathrm{keV}\left({ }^{88} \mathrm{Y}\right)$ の間では 効率の対数值 $(\log \varepsilon)$ と $\gamma$ 線エネルギーの対数值 $(\log E)$ はよい直線関係にある。この関係を $\log \varepsilon=\log B-K \log$. 
$E$ で近似し, 最小 2 乗法によって $B$ および $K$ の值を求 め, 結果を Table 1 に示した。

\section{III 考察}

\section{1. 測定結果の関数近似}

比較的低いエネルギーの $\gamma$ 線の場合は, 位置に対する 効率変化はェネルギーによって異なっており, 簡単な関 数近似はむずかしい。一方, 比較的高いエネルギーの $r$ 線の場合, 位置に対する効率変化と, エネルギーに対す る効率変化は互いに独立とみることができ, 簡単な関数 近似が可能となる。

${ }^{137} \mathrm{Cs}(\gamma: 662 \mathrm{keV}),{ }^{54} \mathrm{Mn}(\gamma: 835 \mathrm{keV}),{ }^{60} \mathrm{Co}(\gamma:$ $1,332 \mathrm{keV})$ の $\gamma$ 線に対する測定結果は, Fig. 2 に示さ れる薄墨の範囲で, 次式で近似的に表わすことができ る。

$$
\begin{gathered}
\varepsilon=\frac{C}{R^{2}} E^{-K} \\
R^{2}=(X+\Delta X)^{2}+Y^{2}
\end{gathered}
$$

ここで $\varepsilon:$ 全エネルギーピーク効率

$E:$ 入射 $\gamma$ 線のエネルギー $(\mathrm{keV})$

$X:$ 検出器表面から線源までの距離 $(\mathrm{cm})$

$\Delta X:$ 検出器表面から実行中心までの距離 $(\mathrm{cm})$

$Y:$ 検出器中心軸から線源までの距離 $(\mathrm{cm})$

$C, K:$ 検出器によって定まる定数

$\Delta X=2 \mathrm{~cm}$ とし, 測定值を $R^{2} \times \varepsilon$ に変換し最小 2 乗 近似すると, $K=1.16, C=171$ の值が得られた。このと きの最大誤差は $12 \%$ ，標準䛊差は $5 \%$ であった。

\section{2. 効率の推定}

効率が (1)式で表わされるものとし， $C$ 拈よび $K$ を 推定してみる。通常, $\mathrm{Ge}(\mathrm{Li})$ 半導体検出器の規格とし

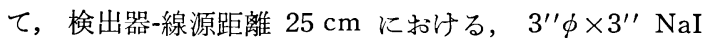
(T1) 検出器に対する ${ }^{60} \mathrm{Co}\left(E_{\gamma}=1,332 \mathrm{keV}\right)$ の相対効率 $\left(\varepsilon_{\mathrm{RN}}\right)$ が示されている。 $\mathrm{NaI}(\mathrm{Tl}) 3^{\prime \prime} \phi \times 3^{\prime \prime}$ 検出器の全 エネルギーピーク効率が $1.2 \times 10^{-31)}$ であることを用い ると,（1 )式から

$$
C=1.2 \times 10^{-3} \cdot(25+\Delta X)^{2} \frac{\varepsilon_{\mathrm{RN}}}{1,332^{-K}}
$$

となる。いま， $K$ および $\Delta X$ が実験的に求められてい るとし，マニュアル (カタログ) データの $\varepsilon_{\mathrm{RN}}=0.0465$ を代入すると $C=171$ となり，実験值とよく一致する。

$K$ の值が実験的に求められていない場合, E. VANO ${ }^{1)}$ らの提案する次式から $K$ を求める。

$$
K=2.13-0.629 \log \left(V_{a}\right)
$$

ここで $V_{a}$ は有効体積 (cc) である。（4)式を用いて $V_{a}=28.3 \mathrm{cc}$ を代入すると， $K=1.22$ となり，実験値と の誤差は $5 \%$ である。この $K$ 值を $(3)$ 式に代入すると, $C=264$ を得る。これらの值を用いると $122 \mathrm{keV〜2,734}$ $\mathrm{keV}$ の範囲では, 実験的に求めた前述の值を用いた場合 に対する効率の最大誤差は $13 \%$ となった。

\section{3. 効率推定に伴う誤差について}

ある距離で求められた $K$ 抢よび $C$ に誤差を含んでい るとし，かつ $C$ は土ネルギー $E_{0}$ で求められた効率を用 いて算出されたとすれば，測定効率の相対䛊差 $\Delta \varepsilon_{\mathrm{R}}$ は (1)式より

$$
\Delta \varepsilon_{\mathrm{R}}=\left(1+\frac{\Delta C}{C}\right) E^{-\lrcorner K}-1=\left(1+\Delta \varepsilon_{\mathrm{OR}}\right)\left(\frac{E}{E_{0}}\right)-\Delta K-1
$$

となる。右辺の定数を左辺に移行し，対数をとると， $\log \left(\Delta \varepsilon_{\mathrm{R}}+1\right)$ と $\log E$ とは線形となり， $\Delta \varepsilon_{\mathrm{R}}+1$ の最大 值, 最小值は $E$ の境界で得られることになる。従って, $E_{1} \leq E \leq E_{2}$ とすれば， $\left|\Delta \varepsilon_{\mathrm{R}}\right|$ の最大值は次の式で表わさ れる。

$$
\begin{gathered}
\operatorname{Max}\left|\Delta \varepsilon_{\mathrm{R}}\right|=\operatorname{Max}\left\{\left|\left(1+\Delta \varepsilon_{\mathrm{OR}}\right)\left(\frac{E_{1}}{E_{0}}\right)-\Delta K-1\right|,\right. \\
\left.\left|\left(1+\Delta \varepsilon_{\mathrm{OR}}\right)\left(\frac{E_{2}}{E_{0}}\right)-\Delta K-1\right|\right\}
\end{gathered}
$$

$\Delta K, \Delta C: K$ および $C$ の誤差 $\Delta \varepsilon_{\mathrm{OR}}: E_{0}$ における $\varepsilon$ の相対誤差

マニュアル（カタログ）データを使用することを前提 として, $\operatorname{Max}\left|\Delta \varepsilon_{\mathrm{R}}\right|$ を求めてみる。マニュアル（カタロ グ）に示される有効体積は，通常必ずしも正確ではな い。いま，この誤差を $\pm 5 \%$ と見積ると，(4)式の微分 形から $\Delta K$ が $\pm 3.2 \%$ となることが導かれる。 $\mathrm{E}$. VANO らが報告するように，（4）式が $3 \%$ 誤差をもって いるとし，これらの誤差が独立にランダムに現われると すれば, $\Delta K=\left(3.2^{2}+3^{2}\right)^{1 / 2}=4.4 \approx 5 \%$ と見積ることが でさる。そこで $\Delta K, \Delta \varepsilon_{O R}$ を $5 \%$ と見積り， $E_{1}=$ $200 \mathrm{keV}, E_{2}=3,000 \mathrm{keV}, E_{0}=1,332 \mathrm{keV}$ とすれば，最 大䛊差は $E=E_{1}$ で現われ, $\operatorname{Max}\left|\Delta \varepsilon_{\mathrm{R}}\right|=0.16(16 \%)$ と なる。 $\operatorname{Max}\left|\Delta \varepsilon_{\mathrm{R}}\right|$ は $E_{0}$ の值によって変るが，もし $E_{0}$ が任意に選べるとすれば， $\log \varepsilon$ と $\log E$ が直線関係で 表されるとしたことから推測でさるように， $E_{0}=\left(E_{1}\right.$. $\left.E_{2}\right)^{1 / 2}$ とすればよいことが(6)式から導かれる*2。

*1 $K \doteqdot 1$ とし， $\Delta K / K \doteqdot \Delta K$ としている。

*2 $A C$ と $A K$ のあらゆる付号の組合せを(6)式に入れると, 8 個の值が求まる。このらち 4 個は, その大小関係から 省略ができ，残りの 4 個は $E_{0}$ に対して単調増加の組と 単調減少にわけられ, 結局, $j \varepsilon_{\mathrm{R}}$ が等しい点で最小とな る。 


\section{IV 結 論}

$28 \mathrm{cc}$ 同軸型半導体検出器の 全エネルギーピーク効率 は, ${ }^{137} \mathrm{Cs}(\gamma: 662 \mathrm{keV}),{ }^{54} \mathrm{Mn}(r: 835 \mathrm{keV}),{ }^{60} \mathrm{Co}(r:$ 1,332 keV) の点線源に対して, Fig. 2 に薄墨で示され る範用内で $(1$ )式で近似することができ, 等感度面は球 面となった。このときの最大誤差は $12 \%$ ，標準誤差は $5 \%$ であった。 $K$ の值が実験的に求められたと仮定し, マニュアル (カタログ) データからCを求めると, 実験 的に求めた值との差は $1 \%$ 以下であった。実験值が全く ないことを仮定し，E. VANO らの式とマニュアル（カ タログ）データから测定効率を求めると, $122 \mathrm{keV〜}$ $2,734 \mathrm{keV}$ の範囲で実験的に求めた式の值との最大誤差 は $13 \%$ であった。

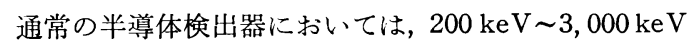

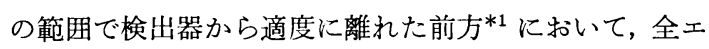
ネルギーピーク効率は（1）式で近似できると考えられ $ろ^{2 \sim 6) * 2}$ 。このとき実験值がない場合においても, 点線 源に対する全エネルギーピーク効率は, 有効体積 $\left(V_{a}\right)$, $3^{\prime \prime} \phi \times 3^{\prime \prime} \mathrm{NaI}(\mathrm{Tl})$ に対する相対効率 $\varepsilon_{\mathrm{RN}}$ から推定する ことができる。（1）式で全エネルギーピーク効率が完全 に表わされるものとしたとき，推定に伴ら最大誤差は (6) 式で表わされ, 前述の $V_{a}$ および $\varepsilon_{\mathrm{RN}}$ の誤差を $5 \%$ としてみると, 効率の最大䛊差は $16 \%$ となる。このよ うな効率の推定值は测定に際して良い目安となり，その 推定值を用いて放射能の絶対值を推定することが可能で あり，また効率較正時の手数を大幅に減ずることができ ると考えられる。

\section{付 録}

\section{(5) 式の説明}

(1)式を用いると

*1 お拉よそ検出器の長さ程度離れ, 中心軸からの開角が $45^{\circ}$ 以内の範囲。

*2 有効体積が大きくなる之, 近似が悪くなる傾向が見られ る。

$$
\begin{aligned}
\Delta \varepsilon_{\mathrm{R}} & =\frac{\varepsilon^{\prime}-\varepsilon}{\varepsilon}=\frac{\varepsilon^{\prime}}{\varepsilon}-1=\frac{C^{\prime} \cdot E^{-K^{\prime}} / R^{2}}{C \cdot E^{-K} / R^{2}}-\mathrm{I} \\
& =\frac{C^{\prime}}{C} E^{-\left(K^{\prime}-K\right)}-1=\left(1+\frac{\Delta C}{C}\right) E^{-\Delta K}-1
\end{aligned}
$$

ここで

$\varepsilon^{\prime}, K^{\prime}$ および $C^{\prime}$ は，それぞれ䛊差を含む効率，Kお よび $C$ とする。また， $E_{0}$ の 1 点で絶対効率 $\varepsilon^{\prime}\left(E_{0}\right)$ が 求められており, それが $\Delta \varepsilon_{\mathrm{OR}}$ の相対䛊差をもっている. とすれば

$$
\begin{aligned}
& \varepsilon^{\prime}\left(E_{0}\right)=\varepsilon\left(E_{0}\right)\left(1+\Delta \varepsilon_{\mathrm{OR}}\right) \\
& C^{\prime} \cdot E_{0}{ }^{-K^{\prime}} / R^{2}=C \cdot E_{0}{ }^{-K} / R^{2}\left(1+\Delta \varepsilon_{\mathrm{OR}}\right) \\
& C^{\prime} \\
& C^{-}=E_{0} \Delta K\left(1+\Delta \varepsilon_{\mathrm{OR}}\right)
\end{aligned}
$$

$\left(5^{\prime \prime}\right)$ を $\left(5^{\prime}\right)$ に代入すれば

$$
\left.\Delta \varepsilon_{\mathrm{R}}=\left(1+\Delta \varepsilon_{\mathrm{OR}}\right)\left(\frac{E}{E_{0}}\right)-\right\lrcorner K-1
$$

となる。

\section{参考文 献}

1) E. Vano, L. Gonzalez, R. Gaeta and J.A. GoNZALEZ; Nucl. Instr. and Meth., 123, 573. (1975).

2) H. Seyfarth, A.M. Hassan, B. Hrastnik, P. Gottel and W. Delang; Nucl. Instr. and Meth., 105, 301 (1972).

3) G. Aubin, J. Barrete, G. Lamourex and S. MONARO; Nucl. Instr. and Meth., 76, 85 . (1969).

4) G. Wallage and G.E. CoOte; Nucl. Instr. and Meth., 74, 353 (1969).

5) F. ADAMS and R. DAMS; "Applied GammaRay Spectrometry," 2nd ed., p. 201 (1970). Pergamon Press.

6) 小林久伸; 原子力工業, 18(7), 75 (1972). 